\title{
ANÁLISE DOS FATORES DISCRIMINANTES DO CRESCIMENTO URBANO DOS MUNICÍPIOS DO SUDOESTE DO PARANÁ NO PERÍODO 2000-2010
}

\section{ANALYSIS OF THE DISCRIMINANT FACTORS OF THE URBAN GROWTH OF THE COUNTY OF SOUTHWEST OF THE PARANÁ IN THE PERIODO OF 2000- 2010}

\author{
Édina Fankhauser, ${ }^{1}$ \\ Cármem Ozana de Melo ${ }^{2}$
}

\section{RESUMO}

Esta pesquisa propôs-se a analisar os motivos pelos quais alguns municípios da região sudoeste do Paraná apresentaram crescimento populacional, sendo mais dinâmicos, e outros tiveram taxas negativas de crescimento populacional. Logo, busca-se determinar os fatores que diferenciam os municípios com crescimento daqueles com crescimento negativo, a partir de características socioeconômicas, considerando dois períodos distintos - 2000 e 2010. Esta análise foi feita a partir da Análise Discriminante, dividindo os 42 municípios da região sudoeste em três grupos: dinâmicos (grupo 1), estáveis (grupo 2) e deprimidos (grupo 3). Foram determinadas oito variáveis selecionadas a partir de dados secundários obtidos através do IPARDES. Os resultados da pesquisa demostram que a discriminação entre os municípios ocorre por conta da concentração populacional (densidade demográfica) e o grau de industrialização. Ambos os fatores podem se tornar atrativos para novos habitantes que estão em busca de melhores condições de vida, melhores oportunidades de trabalho, aumento de renda e educação, ou seja, em busca de uma qualidade de vida melhor.

Palavras chave: Análise discriminante. Crescimento urbano. População urbana. Urbanização.

\section{ABSTRACT}

This research proposed to analyze the reasons why some counties of the southwestern region of Paraná presented population growth, being more dynamic, and others had negative rates of population growth. Thus, it is seek to determine the factors that differentiate the counties with growth from those with negative growth, based on socioeconomic characteristics, considering two distinct periods - 2000 and 2010. This analysis was made using the multivariate statistical method called Discriminant Analysis, dividing the 42 counties of the Southwest region into three groups: dynamic (group 1), stable (group 2) and depressed (group 3). Eight variables were selected from secondary data obtained through IPARDES. The results of the research show that the discrimination between counties occurs due to population concentration (population density) and the degree of industrialization. Both factors become attractive to new residents who are looking for better living conditions, better job oportunities, increased income and education, that is in search of a better quality of life.

Key words: Discriminant analysis. Urban growth. Urban population. Urbanization.

\footnotetext{
1 Unioeste - Universidade do Oeste do Paraná. e-mail : arquitetaedinaf@gmail.com
}

2 Unioeste - Universidade do Oeste do Paraná. e-mail : carmem.melo@unioeste.br 
JEL Classification: C38. J11. R23

\section{INTRODUÇÃO}

O crescimento urbano mundial tem se tornado cada vez mais intenso, a população que vive nas cidades é maior do que aquela que vive no meio rural, e a tendência, segundo as Nações Unidas (2012), é que essa diferença aumente nos próximos anos. Em pesquisa divulgada em 2014 pela ONU (Organização das Nações Unidas), dos mais de 7,2 bilhões de habitantes no mundo, $53,6 \%$ viviam no meio urbano. Esta mesma pesquisa indica que até 2030 , das 8,6 bilhões de pessoas, $70 \%$ viverá em cidades (UNITED NATIONS, 2014), e que esse crescimento ocorrerá principalmente em países que estão em desenvolvimento.

A predominância da população urbana tem gerado novas demandas sociais, e novas formas de redistribuição espacial em todo o mundo, e não poderia ser diferente em território nacional. Até os anos 1970, o processo de urbanização brasileiro esteve condicionado ao crescimento acelerado e progressivo das grandes cidades e metrópoles, algo que vem mudando gradativamente ao longo do tempo, onde não apenas as grandes metrópoles apresentam crescimento, mas também cidades pequenas e médias (BAENINGER, 2011).

Neste cenário de crescimento urbano nacional, onde alguns estados vêm sendo urbanizados já a um longo período, o estado do Paraná, localizado na região Sul do Brasil, apresenta uma história de colonização e urbanização recentes. No século XVI, a ocupação populacional ocorria apenas no litoral, e onde hoje é a capital do estado, Curitiba (SILVA; BULHÕES, 2012). Já no sudoeste paranaense, a ocupação iniciou-se a partir de 1900, como resultado de fluxos migratórios de caboclos provenientes de Guarapuava (cidade localizada na região central do estado) Rio Grande do Sul e Santa Catarina (SILVA; BULHÕES, 2012).

Atualmente a região Sudoeste é composta por 42 municípios, e ao observarse a dinâmica do fenômeno de urbanização, verifica-se que a população urbana vem aumentando gradativamente, elevando-se assim a taxa de urbanização. No entanto a população total de muitos destes municípios, principalmente os menores, está diminuindo. A grande maioria perdeu população ou manteve-se estável ao longo do tempo. Os municípios que apresentaram um incremento populacional considerável, foram justamente aqueles considerados polos da região, que são Francisco Beltrão, Palmas e Pato Branco (IPARDES, 2017).

Este movimento de população para os maiores centros, ocasionam perda de dinamismo nos menores municípios, podendo gerar vazios, com reflexos no desenvolvimento regional. De acordo com dados do censo demográfico 2010, dos 42 municípios da região, 24 tiveram taxas negativas de crescimento populacional, ocasionando o esvaziamento de alguns, com concentração nos maiores.

A constatação do fato de que os municípios da região vêm sofrendo continuamente queda da taxa de crescimento populacional, enquanto outros apresentam crescimento populacional, torna intrigante a questão dos fatores que podem levar a ocorrência desse fenômeno. Tal contexto traz inquietações que remetem a reflexões como: o que leva à concentração de pessoas e atividades econômicas em determinados municípios? Quais características poderiam diferenciar os municípios dinâmicos daqueles deprimidos, de modo que os primeiros atraiam para si pessoas e atividades econômicas, em detrimento dos outros? Neste sentido, esta 
pesquisa indaga: por que alguns municípios da região foram mais bem-sucedidos que outros, quando se fala em crescimento urbano?

A fim de responder este questionamento, tem-se como objetivo analisar os motivos pelos quais alguns municípios da região apresentaram crescimento e outros tiveram taxas negativas de crescimento populacional. Sendo assim, busca-se determinar os fatores que diferenciam os municípios com crescimento daqueles com crescimento negativo, a partir de características socioeconômicas, considerando dois períodos distintos - 2000 e 2010.

Para responder aos objetivos da pesquisa é utilizada a Análise Discriminante. Para tanto, são considerados três grupos de municípios, definidos a priori a partir da taxa de crescimento geométrico de cada um, onde: o grupo um, compreende aqueles municípios com crescimento geométrico acima de $0,5 \%$, o grupo dois, são os que mantiveram crescimento estável, entre $0,5 \%$ e $-0,5 \%$, já o grupo três, são os muncípios com crescimento geométrico abaixo de $-0,5 \%$.

Diante disso, o estudo justifica-se por buscar contribuir para a literatura quanto ao crescimento econômico urbano das cidades que compõe a região sudoeste do Paraná, alinhando-o à questão espacial como fundamental para o entendimento a respeito de quais fatores que influenciam o crescimento, ou a perda de população e dinamismo dos munícipios. Por se tratar de uma pesquisa de caráter exploratório, não se apresenta uma hipótese a ser verificada.

\section{REFERENCIAL TEÓRICO}

\section{A nova geografia econômica}

A distribuição das atividades humanas, desde o surgimento das primeiras civilizações tem ocorrido de forma desigual. A vida econômica de uma região acaba por concentrar-se em um número limitado de assentamentos humanos, as cidades. Essas aglomerações podem ser grandes ou pequenas, dependendo das combinações que ocorrem entre domicílios, indústrias, empresas e áreas agrícolas (THISSE, 2011). Com o intuito de explicar como ocorre a distribuição das atividades econômicas no espaço, como as cidades se formam e qual a relação espacial entre elas, no final da década de 1980 surgiu a Nova Geografia Econômica (CRUZ, 2011).

Essa teoria foi desenvolvida por Krugmam, Fujita e Venables, baseados nas teorias da localização de Von Thunem, Christaller e Losch, e na causação circular de Myrdal, incorporando ainda estruturas de equilíbrio geral e a dimensão espacial. Os autores partem da ideia de que o espaço é homogêneo, e a partir disso avaliam se a dinâmica econômica é capaz de justificar a concentração ou dispersão de atividades, bem como a formação de novas cidades, a formação das hierarquias urbanas, e como esses fatores se relacionam com as desigualdades que ocorrem na distribuição espacial (FUJITA; KRUGMAN; VENABLES, 2002).

O estudo dessas desigualdades regionais, está baseado em duas forças contrárias. As forças centrípetas (custos de transporte, economias de localização, externalidades de conhecimento e economias de urbanização), que levam à aglomeração das atividades em uma determinada região, e as forças centrífugas (custo de terras próximas a aglomerações, salários altos para trabalhadores e surgimento de sindicatos), que levam a dispersão das atividades entre as regiões (OLIVEIRA, 2005).

De acordo com Krugman (1993) no estágio inicial da urbanização e desenvolvimento, a concentração das atividades tende a aumentar devido à escassez 
de infraestrutura econômica (estradas, trabalhadores qualificados, etc.). A partir de um determinado momento, quando as cidades cresceram a ponto de não mais garantir a qualidade de vida da população, essas atividades passariam a se dispersar. Para Fujita, Krugman e Mori (1999) isto demostra que há um ponto ótimo para o crescimento das regiões e cidades, pois poderia se chegar a níveis de crescimento, que trariam como resultado uma série de problemas urbanos.

\section{O desenvolvimento urbano brasileiro}

No início do século XX a urbanização mundial era pouco expressiva, a década de 1950 trouxe consigo uma série de modificações na sociedade, fazendo com que o ritmo de crescimento urbano mundial se acelerasse, principalmente nos países em desenvolvimento. Os motivos para essa intensa urbanização foram, desde heranças históricas até a modernização econômica, política e territorial (ELIAS; PEQUENO, 2013).

Em território nacional, até 1950 a rede urbana era pouco significante em termos de número e tamanho de cidades. As regiões que apresentavam uma urbanização mais densa e dinâmica eram os estados de São Paulo e Rio de Janeiro, onde o transporte rodoferroviário favoreceu a formação e desenvolvimento de um sistema urbano interligado e integrado (MATOS; BAENINGER, 2004).

Já a partir dos anos 1960 e acompanhando a tendências mundiais, o Brasil apresentou um crescimento urbano, oriundo principalmente do desenvolvimento industrial de determinadas regiões, como as regiões metropolitanas das capitais, e também da modernização agrícola, que provocou uma forte concentração de terra, expulsando enorme contingente populacional do campo para a cidade (BAENINGER, 2011). O desenvolvimento industrial dessas regiões, concentrou também os maiores índices de desenvolvimento econômico e incremento populacional (DANTAS; CLEMENTINO, 2013).

Segundo Souza, Moreira e Gasparini (2009), apesar do grande crescimento populacional urbano brasileiro apresentado ao longo do tempo, isso não ocorreu de forma homogênea, fazendo com que algumas regiões apresentassem maior crescimento populacional que outras, como pode ser observado na Tabela 1. A região sudeste, por exemplo, é a que apresenta a maior concentração populacional total e urbana, durante todo o período apresentado na Tabela 1. 
Tabela 1 - Crescimento populacional regional brasileiro - 1960 a 2010 ("população em milhares)

\begin{tabular}{|c|c|c|c|c|c|c|}
\hline Período & Região & Norte & Nordeste & Sudeste & Sul & Centro-oeste \\
\hline \multirow{5}{*}{1960} & Urbana & 1.142 & 7.681 & 17.819 & 4.470 & 996 \\
\hline & $\%$ & $37,68 \%$ & $34,24 \%$ & $57,36 \%$ & $37,59 \%$ & $37,16 \%$ \\
\hline & Rural & 1.889 & 14.749 & 13.245 & 7.423 & 1.684 \\
\hline & $\%$ & $62,32 \%$ & $65,76 \%$ & $42,64 \%$ & $62,41 \%$ & $62,84 \%$ \\
\hline & Total & 3.031 & 22.430 & 31.064 & 11.893 & 2.680 \\
\hline \multirow{5}{*}{1970} & Urbana & 1.785 & 11.981 & 29.348 & 7.435 & 2.359 \\
\hline & $\%$ & $42,60 \%$ & $41,78 \%$ & $72,76 \%$ & $44,56 \%$ & $50,94 \%$ \\
\hline & Rural & 2.405 & 16.695 & 10.985 & 9.250 & 2.272 \\
\hline & $\%$ & $57,40 \%$ & $58,22 \%$ & $27,24 \%$ & $55,44 \%$ & $49,06 \%$ \\
\hline & Total & 4.190 & 28.676 & 40.333 & 16.685 & 4.631 \\
\hline \multirow{5}{*}{1980} & Urbana & 3.399 & 17.960 & 43.551 & 12.154 & 4.951 \\
\hline & $\%$ & $50,22 \%$ & $50,71 \%$ & $82,83 \%$ & $62,71 \%$ & $70,68 \%$ \\
\hline & Rural & 3.369 & 17.460 & 9.030 & 7.227 & 2.054 \\
\hline & $\%$ & $49,78 \%$ & $49,29 \%$ & $17,17 \%$ & $37,29 \%$ & $29,32 \%$ \\
\hline & Total & 6.768 & 35.420 & 52.581 & 19.381 & 7.005 \\
\hline \multirow{5}{*}{1991} & Urbana & 5.932 & 25.754 & 55.150 & 16.393 & 7.649 \\
\hline & $\%$ & $57,83 \%$ & $60,64 \%$ & $88,01 \%$ & $74,12 \%$ & $81,26 \%$ \\
\hline & Rural & 4.326 & 16.717 & 7.512 & 5.725 & 1.764 \\
\hline & $\%$ & $42,17 \%$ & $39,36 \%$ & $11,99 \%$ & $25,88 \%$ & $18,74 \%$ \\
\hline & Total & 10.258 & 42.471 & 62.662 & 22.118 & 9.413 \\
\hline \multirow{5}{*}{2000} & Urbana & 9.003 & 32.930 & 65.442 & 20.307 & 10.076 \\
\hline & $\%$ & $69,82 \%$ & $69,04 \%$ & $90,52 \%$ & $80,93 \%$ & $86,73 \%$ \\
\hline & Rural & 3.891 & 14.764 & 6.856 & 4.784 & 1.542 \\
\hline & $\%$ & $30,18 \%$ & $30,96 \%$ & $9,48 \%$ & $19,07 \%$ & $13,27 \%$ \\
\hline & Total & 12.894 & 47.694 & 72.298 & 25.091 & 11.618 \\
\hline \multirow{5}{*}{2010} & Urbana & 11.665 & 38.823 & 74.697 & 23.261 & 12.483 \\
\hline & $\%$ & $73,53 \%$ & $73,14 \%$ & $92,95 \%$ & $84,93 \%$ & $88,79 \%$ \\
\hline & Rural & 4.200 & 14.261 & 5.669 & 4.126 & 1.576 \\
\hline & $\%$ & $26,47 \%$ & $26,86 \%$ & $7,05 \%$ & $15,07 \%$ & $11,21 \%$ \\
\hline & Total & 15.865 & 53.084 & 80.366 & 27.387 & 14.059 \\
\hline
\end{tabular}

Fonte: IBGE (2017).

Nesse contexto de rápida urbanização e crescimento heterogêneo, o modelo de urbanização brasileiro, caracterizou-se por disparidades socioespaciais, ineficiência e grande degradação ambiental. As dinâmicas econômicas recentes estão desafiando as cidades a absorverem esse crescimento, melhorando suas condições urbanísticas do ponto de vista territorial, considerando que urbanizar não é apenas expandir (ROLNIK; KLINK, 2011).

Afim de entender como tem ocorrido esse crescimento urbano, diversas pesquisas já foram desenvolvidas, tanto no Brasil quanto no mundo. As técnicas estatísticas e metodologias utilizadas variam muito de acordo com o objetivo que se pretende responder. São utilizadas desde a regressão linear, econometria espacial, cluster e a análise discriminante. Em muitas pesquisas há ainda a utilização de mais de uma técnica estatística.

A pesquisa de Vieira (2009), investiga por quais motivos algumas cidades no estado de São Paulo são mais dinâmicas que outras, levando em consideração a demografia (perda ou ganho de população) e a economia (desempenho do PIB). Ele busca responder se esse dinamismo, ou a falta dele, está relacionado a forças externas, ou a esforços internos de políticas públicas nesse processo.

Já Souza, Moreira e Gasparini (2009), investigaram quais as forças determinantes do crescimento econômico urbano brasileiro em grandes e médias cidades, no período de 1970 a 2000. Os autores buscam fazer uma análise da relação 
entre o crescimento populacional urbano e a renda familiar per capita com as características apresentadas por essas cidades no início do período (demografia, educação, infraestrutura, atividade econômica, mercado de trabalho, grau de industrialização, desigualdade de renda e características urbanas).

Ambas as pesquisam ressaltam a importância para o desenvolvimento de políticas públicas voltadas para a melhoria da educação, da industrialização e da infraestrutura dos municípios brasileiros, como um meio de favorecer o crescimento econômico urbano, assim como o desenvolvimento de políticas públicas diferenciadas para cada cidade.

\section{A urbanização no estado do Paraná}

A emancipação política do Paraná, ocorreu no ano de 1853, e a partir desse período, sua configuração territorial sofreu uma série de alterações, principalmente no que diz respeito a divisão municipal. No ano de 1940 eram 50 municípios, passando para 162 em 1960, 290 em 1980 e 399 no ano de 2000 (FIRKOWSKI, 2005). Esses 399 municípios estão divididos em dez regiões geográficas e três regiões metropolitanas ${ }^{3}$. Mesmo depois da criação desses novos municípios, tem ocorrido, na grande maioria deles um processo de esvaziamento populacional, acompanhado de grande concentração na Região Metropolitana de Curitiba e demais regiões que apresentem vantagens competitivas e oportunidades de melhoria na qualidade de vida da população. (FIRKOWSKI, 2005).

De acordo com Cintra et al. (2010), em análise feita ao censo demográfico 2010 , apenas $7 \%$ dos municípios paranaenses apresentaram taxas de crescimento superiores às do estado, e são justamente municípios que estão localizados em uma das regiões metropolitanas institucionalizadas. Em contrapartida, 44\% ou 177 municípios apresentaram perda de população, indicando que são poucos e concentrados os que dão suporte às dinâmicas mais relevantes do Paraná (CINTRA et al., 2010). Os municípios que perderam população em sua grande maioria, são aqueles que tem menos de 5 mil habitantes.

Baseados nos resultados do censo demográfico, Costa e Rocha (2014) desenvolveram uma classificação para os 399 municípios do estado, levando em consideração a dinâmica socioespacial e econômica. Eles dividiram os municípios em fortemente dinâmicos, dinâmicos, intermediários e periféricos, utilizando os seguintes indicadores: influência das cidades, relevância econômica, índice IPARDES de Desempenho Municipal - IPDM, taxa de pobreza e crescimento geométrico da população (COSTA; ROCHA, 2014).

Fortemente dinâmicos são aqueles municípios que exercem elevada influência na rede urbana e são os principais centros industriais, comerciais e de prestação de serviços, atraindo investimentos públicos e privados. Os municípios dinâmicos exercem influência regional e atuam como centros industriais, comerciais e de prestação de serviços, como são regiões em desenvolvimento, atraem investimentos públicos e privados. Os municípios intermediários são aqueles que atendem as necessidades básicas da população como centros locais, apresentando

\footnotetext{
${ }^{3}$ Regiões geográficas: Noroeste Paranaense, Centro-Ocidental Paranaense, Norte Central Paranaense - na qual se inserem as RMs de Maringá e de Londrina -, Norte Pioneiro Paranaense, Centro-Oriental Paranaense, Oeste Paranaense, Sudoeste Paranaense, Centro-Sul Paranaense, Sudeste Paranaense e Metropolitana de Curitiba, na qual se encontra a RM de Curitiba.
} 
pouco crescimento populacional, eles podem apresentar dificuldade em atrair capital externo e aproveitar suas potencialidades. Por fim, os municípios periféricos têm influência apenas em seus limites territoriais, possuindo dificuldades para atender as necessidades básicas da população (saúde, educação, emprego, renda, moradia, consumo, etc.), tornando-se necessário o deslocamento dessa população para os municípios intermediários, dinâmicos ou fortemente dinâmicos (COSTA; ROCHA, 2014).

\section{O crescimento urbano na região sudoeste paranaense}

No início do século $X X$ a população do sudoeste paranaense era pouco numerosa, e residia em grande parte nas áreas rurais (MONDARDO; BACKES, 2007). Essa população era formada em sua maioria por caboclos vindos de Guarapuava (cidade localizada na região central do estado) Rio Grande do Sul e Santa Catarina (SILVA; BULHÕES, 2012). Nestes locais os latifúndios já não comportavam esses trabalhadores, restando a eles a alternativa de ir em busca de terras para sobrevivência em outras regiões (MONDARDO, 2011).

Só a partir de 1940, ocorre um fluxo migratório vindo de outras regiões do país, que expande e consolida as fronteiras agrícolas do sudoeste paranaense. Esse fluxo teve origem principalmente em incentivos do governo federal, como o projeto Marcha para Oeste, e através dele a instalação da CANGO - Colônia Agrícola Nacional General Osório 4 (MONDARDO, 2011). Esse crescimento da população rural, fez com que houvesse a expansão de núcleos urbanos, com infraestrutura básica, e que nasciam justamente para dar suporte as atividades agrícolas e, para atender as necessidades de compra e venda dos colonos (MONDARDO, 2007).

$\mathrm{Na}$ década de 1990 conforme afirma Mondardo (2007), os centros urbanos tornam-se mais dinâmicos e especializados, para o escoamento da produção agrícola, o comércio de modo geral, a prestação de serviços, inclusive os serviços públicos. Nesse período a região começa a perder população: em 1980 eram 590.086 habitantes, em 1990 passa a 557.049 habitantes, como é possível observar na Tabela 2 .

Tabela 2 - Evolução populacional no Sudoeste do Paraná de 1980 a 2010

\begin{tabular}{l|c|c|c|c|c}
\hline \multirow{2}{*}{ Ano/População } & Pop. Censitária - & \multicolumn{2}{|c|}{ Pop. Censitária Urbana } & \multicolumn{2}{c}{ Pop. Censitária Rural } \\
\cline { 3 - 6 } & Total & $\mathbf{N}^{\circ}$ hab. & $\mathbf{( \% )}$ & $\mathbf{N}^{\circ}$ hab. & $(\%)$ \\
\hline 1980 & 590.086 & 197.843 & 33,53 & 392.243 & 66,47 \\
1991 & 557.049 & 268.885 & 48,26 & 288.164 & 51,73 \\
2000 & 557.443 & 337.959 & 60,62 & 219.484 & 39,37 \\
2010 & 587.496 & 412.570 & 70,23 & 174.926 & 29,77 \\
\hline
\end{tabular}

FRQMt IPARDES (2017).

Nos anos 2000, a população total mantém-se estável, passando dos seus 557.049 habitantes em 1991 para 557.443 em 2000 (IPARDES, 2017), no entanto a taxa de urbanização mantém-se em crescimento, principalmente nas cidades consideradas polo como Francisco Beltrão, Pato Branco e Palmas. Segundo o IPEA

\footnotetext{
${ }^{4}$ Decreto Presidencial n ${ }^{\mathrm{o}}$ 12.417, de 12 de maio de 1943: "Fica criada a Colônia Agrícola Nacional "General Osório", no Estado do Paraná, na faixa de 60 quilômetros da fronteira, na região Barracão - Santo Antônio, em terras a serem demarcadas pela Divisão de Terras e Colonização, do Departamento Nacional da Produção Vegetal, do Ministério da Agricultura" (LEME, 2015, p. 80).
} 
Análise dos fatores discriminantes do crescimento urbano dos municípios do Sudoeste do Paraná no período 20002010

(2000), a região passa a ser uma área de esvaziamento, pois conta com atividades econômicas em desenvolvimento, que não geram um grande número de postos de trabalho.

\section{METODOLOGIA}

\section{Área de estudo}

Nesta pesquisa, toma-se como área de estudo os municípios da Região Geográfica Sudoeste do Paraná, definida de acordo com a Lei Estadual $n^{\circ} 15.825 / 08^{5}$. Ela está localizada no Terceiro Planalto Paranaense e abrange uma área de $17.060,444 \mathrm{Km}^{2}$, fazendo fronteira a oeste com a República da Argentina, através da foz do rio Iguaçu, ao sul com o estado de Santa Catarina, ao norte com as regiões Oeste e Centro-Sul e ao leste com a região Centro-Sul. É constituída por 42 municípios, conforme Tabela 3 (IPARDES, 2017). A Figura 1 mostra ainda a localização dessa região no estado.

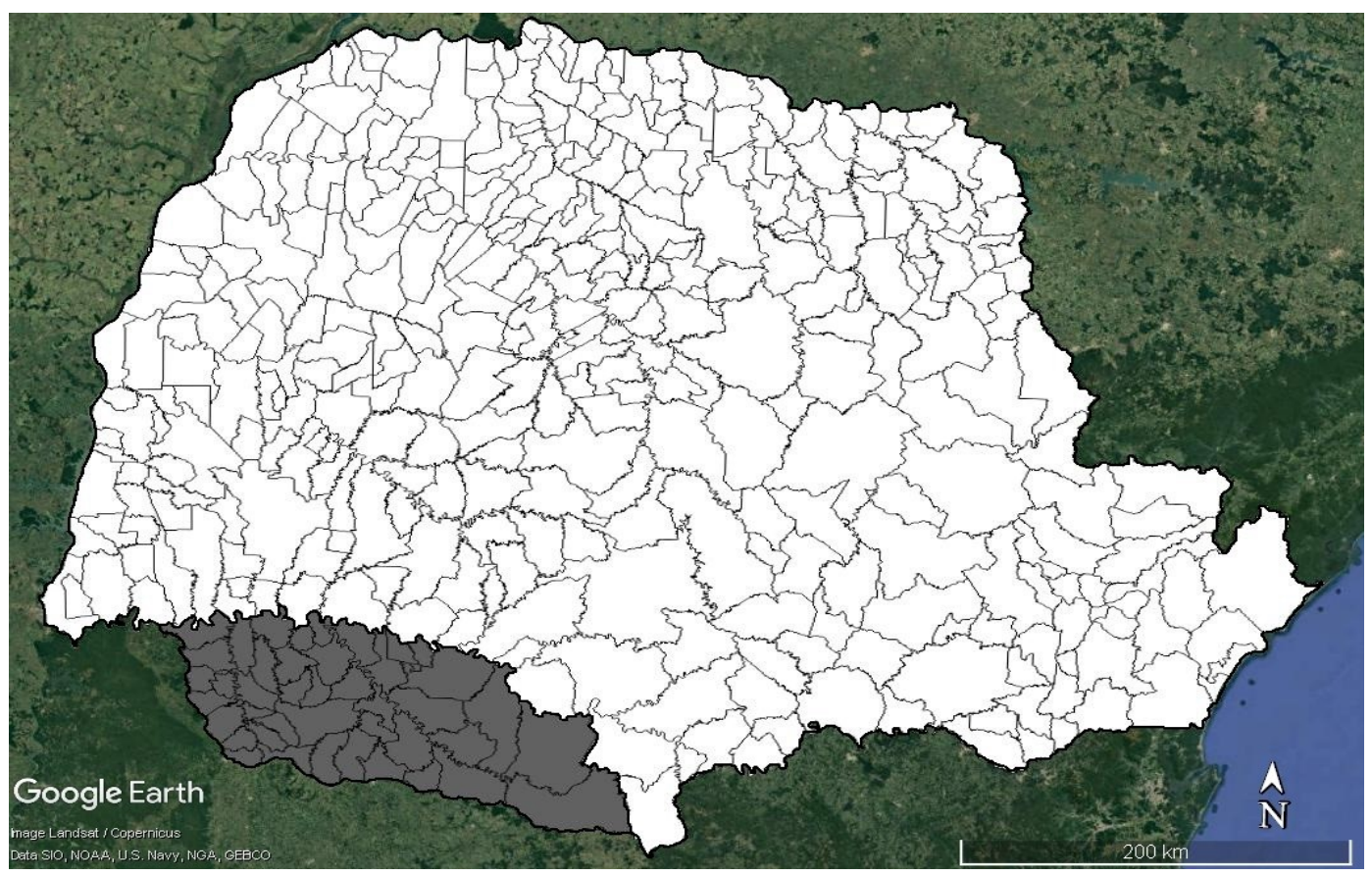

पा山ा山Figura 1 - Mapa da região geográfica do Sudoeste Paranaense

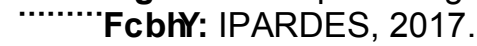

\footnotetext{
${ }^{5}$ Importante ressaltar que há uma diferença entre a divisão da mesorregião Sudoeste Paranaense feita pelo IBGE, composta por 37 municípios e o que determina a Lei Estadual $\mathrm{n}^{\circ} 15.825 / 08$, que inclui os municípios de Clevelândia, Coronel Domingos Soares, Honório Serpa, Mangueirinha e Palmas da Região, retirando-os da mesorregião Centro-Sul. Desta forma a região geográfica Sudoeste do Paraná passa a ser composta por 42 municípios (IPARDES, 2017).
} 
Tabela 3 - Munícipios da região sudoeste paranaense e suas características populacionais

\begin{tabular}{|c|c|c|c|c|c|c|}
\hline \multirow[t]{2}{*}{ Município } & \multicolumn{2}{|c|}{$\begin{array}{c}\text { Taxa de } \\
\text { urbanização }(\%)^{6}\end{array}$} & \multicolumn{2}{|c|}{$\begin{array}{l}\text { População } \\
\text { censitária }\end{array}$} & \multicolumn{2}{|c|}{$\begin{array}{c}\text { Taxa de } \\
\text { Crescimento } \\
\text { geométrico (\%) }\end{array}$} \\
\hline & 2000 & 2010 & 2000 & 2010 & 2000 & 2010 \\
\hline Ampére & 66,59 & 76,59 & 15.623 & 17.308 & 1,90 & 1,03 \\
\hline Barracão & 62,83 & 71,99 & 9.271 & 9.735 & $-0,7$ & 0,49 \\
\hline Bela Vista da Caroba & 16,81 & 26,39 & 4.503 & 3.945 & $-2,04$ & $-1,31$ \\
\hline Boa Esperança do Iguaçu & 18,15 & 34,48 & 3.107 & 2.764 & $-2,35$ & $-1,16$ \\
\hline Bom Jesus do Sul & 9,20 & 24,58 & 4.154 & 3.796 & $-0,65$ & $-0,9$ \\
\hline Bom Sucesso do Sul & 38,53 & 48,01 & 3.392 & 3.796 & $-1,31$ & $-0,3$ \\
\hline Capanema & 51,05 & 60,19 & 18.239 & 18.526 & $-0,67$ & 0,16 \\
\hline Chopinzinho & 51,25 & 63,56 & 20.543 & 19.679 & 0,27 & $-0,43$ \\
\hline Clevelândia & 80,78 & 85,6 & 18.338 & 17.240 & 0,17 & $-0,62$ \\
\hline Coronel Domingos Soares & 11,38 & 24,22 & 7.004 & 7.238 & $-0,33$ & 0,33 \\
\hline Coronel Vivida & 63,21 & 71,01 & 23.306 & 21.749 & $-0,85$ & $-0,69$ \\
\hline Cruzeiro do Iguaçu & 50,39 & 61,31 & 4.394 & 4.278 & $-1,95$ & $-0,27$ \\
\hline Dois Vizinhos & 69,97 & 77,66 & 31.986 & 36.179 & 0,28 & 1,24 \\
\hline Enéas Marques & 19,59 & 34,84 & 6.382 & 6.103 & $-1,72$ & $-0,45$ \\
\hline Flor da Serra do Sul & 11,66 & 34,79 & 5.059 & 4.726 & $-0,36$ & $-0,68$ \\
\hline Francisco Beltrão & 81,68 & 85,44 & 67.132 & 78.943 & 1,03 & 1,63 \\
\hline Honório Serpa & 20,93 & 33,38 & 6.896 & 5.955 & $-1,25$ & $-1,46$ \\
\hline Itapejara d'Oeste & 54,15 & 66,35 & 9.162 & 10.531 & 0,14 & 1,40 \\
\hline Manfrinópolis & 11,78 & 20,85 & 3.802 & 3.127 & $-4,22$ & $-1,94$ \\
\hline Mangueirinha & 36,32 & 49,24 & 17.760 & 17.048 & $-0,08$ & $-0,41$ \\
\hline Mariópolis & 62,67 & 71,30 & 6.017 & 6.268 & $-0,48$ & 0,41 \\
\hline Marmeleiro & 52,46 & 63,48 & 13.665 & 13.900 & $-0,93$ & 0,17 \\
\hline Nova Esperança & 23,28 & 34,21 & 5.258 & 5.098 & $-0,3$ & $-0,31$ \\
\hline Nova Prata do Iguaçu & 51,08 & 58,47 & 10.397 & 10.377 & $-1,23$ & $-0,02$ \\
\hline Palmas & 90,21 & 92,79 & 34.819 & 42.888 & 2,45 & 2,11 \\
\hline Pato Branco & 91,28 & 94,09 & 62.234 & 72.370 & 2,07 & 1,52 \\
\hline Pérola d'Oeste & 36,99 & 47,14 & 7.354 & 6.761 & $-1,25$ & $-0,84$ \\
\hline Pinhal de São Bento & 28,79 & 44,42 & 2.560 & 2.625 & $-1,18$ & 0,25 \\
\hline Planalto & 34,09 & 44,44 & 14.122 & 13.654 & $-0,74$ & $-0,34$ \\
\hline Pranchita & 50,48 & 64,05 & 6.260 & 5.628 & $-1,59$ & $-1,06$ \\
\hline Realeza & 62,10 & 72,2 & 16.023 & 16.338 & $-0,76$ & 0,19 \\
\hline Renascença & 42,08 & 51,16 & 6.959 & 6.812 & $-0,9$ & $-0,21$ \\
\hline Salgado Filho & 40,43 & 51,19 & 5.338 & 4.403 & $-0,72$ & $-1,91$ \\
\hline Salto do Lontra & 43,91 & 54,28 & 12.757 & 13.689 & $-0,91$ & 0,71 \\
\hline Santa Izabel do Oeste & 48,63 & 56,51 & 11.711 & 13.132 & $-0,74$ & 1,15 \\
\hline Santo Antônio do Sudoeste & 60,51 & 72,57 & 17.870 & 18.893 & 0,27 & 0,56 \\
\hline São João & 51,65 & 63,54 & 11.207 & 10.599 & $-2,2$ & $-0,56$ \\
\hline São Jorge d'Oeste & 48,47 & 57,39 & 9.307 & 9.085 & $-1,15$ & $-0,24$ \\
\hline Saudade do Iguaçu & 43,12 & 49,78 & 4.608 & 5.028 & 0,18 & 0,88 \\
\hline Sulina & 30,50 & 40,95 & 3.918 & 3.394 & $-3,17$ & $-1,43$ \\
\hline Verê & 34,73 & 41,65 & 8.721 & 7.878 & $-1,75$ & $-1,01$ \\
\hline Vitorino & 50,76 & 61,23 & 6.285 & 6.513 & $-0,34$ & 0,36 \\
\hline Média Região Sudoeste & 60,63 & 70,23 & 557.443 & 587.49 & 0,01 & 0,53 \\
\hline Média do Estado do & 81,41 & 85,33 & 9.563 .4 & 10.444. & 1,40 & 0,89 \\
\hline
\end{tabular}

\footnotetext{
${ }^{6}$ Taxa de urbanização: porcentagem da população da área urbana em relação à população total (IBGE, 2017)

7 Taxa média geométrica de crescimento anual da população: é o crescimento da população de um local considerando duas datas sucessivas e o intervalo de tempo entre essas datas, medido em ano (IBGE, 2017).
} 
A região como um todo não é homogênea, tanto em seus aspectos naturais quanto a sua formação social (FLORES, 2009). Enquanto alguns municípios apresentam IDH-M ${ }^{8}$ acima da média estadual, outros apresentam índices baixos, demonstrando a maior precariedade nas condições do desenvolvimento humano (IPARDES, 2004). Quanto ao relevo, a região apresenta desde terrenos praticamente planos que permitem a utilização da agricultura mecanizada, até locais com alta declividade, que chegam a inviabilizar a produção agrícola manual. Devido a isso, e como a região possui terras férteis predomina a pequena propriedade familiar, onde há a produção de frutas, gado leiteiro, hortaliças, dentre outras (IPARDES, 2004).

$\mathrm{Na}$ indústria predomina a produção de alimentos, confecções, metalúrgica e moveleiro. Como a região produz uma série de matérias-primas, como milho, frango, trigo e leite, etc. isso facilita e incentiva a instalação de indústrias do ramo na região.

Este panorama da região permite observar as suas características gerais e desperta interesse de se verificar a dinâmica interna de crescimento ocorrida no período de 2000-2010, podendo-se, assim, observar de forma mais pormenorizada as possíveis fontes de diferenças entre os municípios que a integram.

\section{Método de análise - analise discriminante}

De acordo com Fávero et al (2009), a análise discriminante diferencia populações ou amostras em grupos pré-definidos, utilizando critérios que podem ser definidos pelo pesquisador, observando semelhanças entre as observações. Segundo Corrar, Paulo e Dias Filho (2007) essa técnica irá trabalhar com uma variável dependente/qualitativa e outras variáveis independentes/quantitativas, determinando quais são as variáveis que melhor diferenciam uma amostra/população.

Conforme Mingoti (2005), para que essa análise seja aplicada, é necessário conhecer as características gerais do elemento amostral, para que sejam definidos os grupos ao qual cada amostra pertence. Na classificação dos grupos, busca-se uma regra de classificação que minimize o número de classificações incorretas, "ou seja, o erro de dizer que um elemento amostral pertence a uma população quando na realidade pertence a outra" (MINGOTI, 2005).

Como o principal objetivo da $A D$ é a identificação das variáveis que discriminam dois ou mais grupos, ela vai gerar funções discriminantes (combinações lineares das variáveis) que ampliam a discriminação dos grupos descritos pelas variáveis dependentes (FÁVERO et al., 2009). Após a seleção das variáveis discriminantes (explicativas), passa-se à identificação da função discriminante, que é dada pela seguinte equação linear:

$$
Z_{n}=\alpha+\beta_{1} X_{1}+\beta_{2} X_{2}+\cdots+\beta_{n} X_{n}
$$

Em que:

Z: representa a variável dependente categórica;

$\alpha$ : intercepto da reta que representa a função discriminante;

$X_{1}$ : corresponde aos valores das variáveis explicativas/independentes;

\footnotetext{
${ }^{8}$ IDHM: O Índice de Desenvolvimento Humano Municipal, é composto por três dimensões do desenvolvimento humano: a oportunidade de viver uma vida longa (IDHM Saúde); de ter acesso a conhecimento (IDHM Educação) e ter um padrão de vida que garanta as necessidades básicas (IDHM Renda). O índice varia de 0 a 1 , sendo 0 o pior desempenho e 1 o melhor (IPARDES, 2017).
}

72 Economia \& Região, Londrina (Pr), v.7, n.1, p.63-84, jan./jun. 2019 
$\beta_{1}$ : coeficiente discriminante para cada variável explicativa ou a capacidade que cada variável independente tem de discriminar (o peso de cada uma na função).

$\mathrm{Na}$ utilização de métodos computacionais a função discriminante, pode ser feita a partir de dois procedimentos diferentes: o método stepwise e o simultâneo/direto (HAIR et al, 2005). Nesta pesquisa, optou-se pelo método direto, aplicado a partir da modelagem da AD no software Statical Package for the Social Sciences (SPSS ${ }^{\circ}$ V. 18). No método direto todas as variáveis explicativas são consideras conjuntamente no modelo, sem considerar seu poder discriminatório (HAIR et al., 2005; FÁVERO et al., 2009). Como foi realizada uma análise prévia do crescimento urbano a partir de estatísticas descritivas e das diferenças que ocorreram no desenvolvimento dos municípios paranaenses, considerou-se relevante incluir conjuntamente todas as variáveis selecionadas.

\section{Variáveis e fonte dos dados}

Para o desenvolvimento deste estudo fez-se necessário identificar um grupo de variáveis que caracterizassem os 42 municípios, no que se refere ao crescimento urbano. Para a identificação delas foi utilizado como referência as variáveis definidas por Souza, Moreira e Gasparini (2009) e Vieira (2009).

A variável qualitativa (categórica) que dá origem à pesquisa, trata do fenômeno de crescimento ou retração populacional dos municípios do sudoeste paranaense. Para esta variável foi utilizada a taxa de crescimento geométrico total, apresentada pelos municípios no ano de 2010.

Utilizando como referência a pesquisa apresentada por Costa e Rocha (2014), em que os autores classificam os 399 muncípios paranaenses em quatro grupos diferentes (fortemente dinâmicos, dinâmicos, intermediários e periféricos), de acordo com características determinadas para cada grupo, classificou-se os 42 municipios da região sudoeste em três grupos. Foram trabalhados apenas com três grupos e não quatro como Costa e Rocha (2014), pois municípios considerados fortemente dinâmicos, são aqueles que apresentam grande concentração de indústrias, serviços, comércio, logística, etc. e tem influência na economia internacional. Fato esse que não ocorre com a região sudoeste. Quanto às nomenclaturas dos grupos, também foram feitas adaptações, uma vez que o critério de classificação nesta pesquisa foi apenas o crescimento geométrico da população.

Os critérios para a definição de cada grupo são apresentados na sequência:

- Grupo 1: crescimento geométrico acima de 0,5\% - município dinâmico;

- Grupo 2: crescimento geométrico entre -0,5\% e 0,5\% - município estável;

- Grupo 3: crescimento geométrico abaixo de -0,5\% - municípios periféricos.

Conforme os critérios adotados, a classificação de cada município é apresentada atavés do Quadro 1. Essa classificação utilizou apenas os dados para o ano de 2010, para que não houvessem diferenças no tamanho dos grupos, e nem distorções nos resultados. 
Quadro 1 - Munícipios pertencentes a cada grupo

\begin{tabular}{|c|l|l|l|}
\hline & GRUPO 01 & GRUPO 02 & GRUPO 03 \\
\hline 1 & Ampére & Barracão & Bela Vista da Caroba \\
\hline 2 & Dois Vizinhos & Bom Sucesso do Sul & Boa Esperança do Iguaçu \\
\hline 3 & Francisco Beltrão & Capanema & Bom Jesus do Sul \\
\hline 4 & Itapejara d'Oeste & Chopinzinho & Clevelândia \\
\hline 5 & Palmas & Coronel Domingos Soares & Coronel Vivida \\
\hline 6 & Pato Branco & Cruzeiro do Iguaçu & Flor da Serra do Sul \\
\hline 7 & Salto do Lontra & Enéas Marques & Honório Serpa \\
\hline 8 & Santa Izabel do Oeste & Mangueirinha & Manfrinópolis \\
\hline 9 & Santo Antônio do Sudoeste & Mariópolis & Pérola d'Oeste \\
\hline 10 & Saudade do Iguaçu & Marmeleiro & Pranchita \\
\hline 11 & & Nova Esperança do Sudoeste & Salgado Filho \\
\hline 12 & & Nova Prata do Iguaçu & São João \\
\hline 13 & & Pinhal de São Bento & Sulina \\
\hline 14 & & Planalto & Verê \\
\hline 15 & & Realeza & \\
\hline 16 & & Renascença & \\
\hline 17 & & São Jorge d'Oeste & \\
\hline 18 & & Vitorino & \\
\hline
\end{tabular}

Fonte: Dados da pesquisa, 2017.

A partir da análise das pesquisas acima mencionadas, e utilizando a obtenção de dados de forma secundária através da base de dados do IPARDES (Instituto Paranaense de Desenvolvimento Econômico e Social) para os anos de 2000 e 2010, foram selecionadas oito variáveis relacionadas a demografia, saúde da população, economia municipal, educação e infraestrutura urbana, que são apresentadas através do Quadro 2. 
Quadro 2 - Variáveis e suas descrições

\begin{tabular}{|c|c|c|}
\hline & Variável & Descrição \\
\hline \multicolumn{3}{|c|}{ DEMOGRAFIA } \\
\hline 1 & $\begin{array}{l}\text { DENS_DEM - densidade } \\
\text { demográfica (hab./km²) }\end{array}$ & $\begin{array}{l}\text { Determinada pela razão entre a população total de cada } \\
\text { munícipio e a área do mesmo (IPARDES, 2017). }\end{array}$ \\
\hline 2 & THEIL_L - índice de Theil - L & $\begin{array}{l}\text { Índice de desigualdade na distribuição de indivíduos } \\
\text { segundo a renda domiciliar per capita. }\end{array}$ \\
\hline \multicolumn{3}{|c|}{ INFRAESTRUTURA URBANA } \\
\hline 3 & $\begin{array}{l}\text { DOM_ESG - domicílios com } \\
\text { esgotamento sanitário (\%) }\end{array}$ & $\begin{array}{l}\text { Razão entre número de unidades atendidas com coleta de } \\
\text { esgoto e o número de domicílios totais (IPARDES, 2017). }\end{array}$ \\
\hline \multicolumn{3}{|c|}{ ECONOMIA MUNICIPAL } \\
\hline 4 & $\begin{array}{l}\text { PIB_PERCAPITA - Produto } \\
\text { Interno Bruto per Capita (R\$ } \\
1,00)\end{array}$ & $\begin{array}{l}\text { Corresponde ao valor do PIB (Produto Interno Bruto) global } \\
\text { dividido pelo número de habitantes do município } \\
\text { (IPARDES, 2017). }\end{array}$ \\
\hline 5 & $\begin{array}{l}\text { GI -Grau de industrialização } \\
(\%)\end{array}$ & $\begin{array}{l}\text { Razão entre o número de empregos no setor secundário }{ }^{9} \text { e } \\
\text { número de empregos total no ano considerado (SOUZA, } \\
\text { 2006). }\end{array}$ \\
\hline 6 & $\begin{array}{l}\text { RENDA_MED - renda média } \\
\text { domiciliar per capita }(R \$ 1,00)\end{array}$ & $\begin{array}{l}\text { Considera-se como renda domiciliar per capita a soma dos } \\
\text { rendimentos mensais dos moradores do domicílio, dividido } \\
\text { pelo número de moradores (IPARDES, 2017). }\end{array}$ \\
\hline \multicolumn{3}{|c|}{ SAÚDE } \\
\hline 7 & $\begin{array}{l}\text { LEITOS - leitos hospitalares } \\
\text { (\%) }\end{array}$ & $\begin{array}{l}\text { Razão entre o número de leitos hospitalares pela } \\
\text { população total do munícipio. }\end{array}$ \\
\hline \multicolumn{3}{|c|}{ EDUCAÇÃO } \\
\hline 8 & $\begin{array}{l}\text { TX_AN - taxa de } \\
\text { analfabetismo de } 15 \text { anos ou } \\
\text { mais (\%). }\end{array}$ & $\begin{array}{l}\text { Percentual de pessoas analfabetas na faixa etária de } 15 \\
\text { anos ou mais (IPARDES, 2017). }\end{array}$ \\
\hline
\end{tabular}

Fonte: Dados da pesquisa, 2017.

As váriaveis apresentadas no Quadro 2 contribuem também para determinar a qualidade de vida da população, e se há fatores que contribuem para a atratividade de uma cidade para a instalação de novas empresas e investimentos em áreas como saúde, educação, saneamento, etc.

\section{PROCEDIMENTOS METODOLÓGICOS}

A realização desta pesquisa partiu da observação do fato que alguns munícipios da região estavam sofrendo queda de sua população. Tal situação despertou atenção e interesse em investigar o que motiva as pessoas a se deslocarem, gerando, de modo geral, aglomeração em certos lugares, em detrimento de outros.

A delimitação do período 2000 - 2010 deu-se em função das emancipações de 12 municípios, ocorridos na década de 1990. Utilizar um período maior, poderia dar a falsa impressão de que alguns municípios perderam população, quando na verdade tiveram seu território dividido, juntamente com sua população.

\footnotetext{
${ }^{9}$ Dos dados retirados da RAIS, para o setor secundário foram consideradas as seguintes indústrias: indústria de transformação, de produtos minerais e não-metálicos, metalúrgica, mecânica, material elétrico e comunicações, material de transporte, madeira e mobiliário, papel, papelão, editorial e gráfica, borracha, do fumo, de couros, peles e produtos similares, indústria química, produtos farmacêuticos, têxtil, calçados e construção civil (IPARDES, 2017).
} 
A partir das oito variáveis definidas, foi realizada a análise descritiva dos dados, onde verificou-se o que diferenciava cada um dos municípios, independentemente de grupo. Também foi observado quais tem maior destaque dentro da região e concentram mais atividades e serviços à população. Para aplicar a AD foi utilizado o software SPSS.

Como referência para as questões relativas a localização, ou seja, os fatores que contribuem para uma determinada cidade e consequentemente seu espaço urbano apresentarem um desenvolvimento maior, utilizam-se estudos e conceitos baseados em teorias do desenvolvimento econômico como a Nova Geografia Econômica.

Embora para outros estados e regiões brasileiras, e também para outros países, existem vários estudos que demostram estatisticamente as razões do crescimento econômico urbano de determinado local, no caso do Sudoeste Paranaense, isso não ocorre, e não há estudos empíricos disponíveis nessa linha.

\section{RESULTADOS}

\section{Estatística descritiva}

Inicialmente, apresenta-se a análise da estatística descritiva dos dados. Através dela é possível perceber algumas mudanças que ocorreram na região Sudoeste do Paraná no período em estudo, de 2000 a 2010. Na Tabela 4 foi realizado um comparativo entre esse período, para as médias, mínimo e máximo, das variáveis selecionadas para a pesquisa nos 42 municípios. Nesse comparativo é possível perceber como algumas variáveis obtiveram melhor desempenho entre o período inicial e o período final, e como outras mantiveram-se praticamente estáveis.

Tabela 4 - Variáveis do Sudoeste do Paraná e para o estado em 2000 e 2010: média, mínima e máxima

\begin{tabular}{l|l|l|l|l|l|l|l|l}
\hline \multirow{2}{*}{ Variável } & \multicolumn{6}{c|}{ Região Sudoeste do Paraná } & \multicolumn{2}{c}{ Paraná } \\
\cline { 2 - 9 } & \multicolumn{3}{|c|}{ Mínimo } & \multicolumn{2}{c}{ Máximo } & \multicolumn{2}{c}{ Média } & \multicolumn{2}{c}{ Média } \\
\cline { 2 - 9 } & $\mathbf{2 0 0 0}$ & $\mathbf{2 0 1 0}$ & $\mathbf{2 0 0 0}$ & $\mathbf{2 0 1 0}$ & $\mathbf{2 0 0 0}$ & $\mathbf{2 0 1 0}$ & $\mathbf{2 0 0 0}$ & $\mathbf{2 0 1 0}$ \\
\hline DENS_DEM & 4,5 & 4,65 & 115,46 & 134,26 & 33,94 & 34,86 & 47,85 & 52,25 \\
THEIL_L & 0,41 &, 24 & 0,97 & 0,66 & 0,57 & 0,43 & 0,65 & 0,51 \\
DOM_ESG & 0,00 &, 0000 & 0,48 & 0,78 & 0,06 & 0,142 & 0,32 & 0,52 \\
PIB_PER & 3174 & 8929 & 17936 & 197335 & 5813 & 18942 & 9005 & 21562 \\
CAPITA & & & & & & & & \\
GI & 0,00 &, 00 & 0,77 & 0,64 & 0,23 & 0,29 & 0,48 & 0,53 \\
RENDA_ & 188,32 & 342,17 & 723,50 & 974,21 & 399,99 & 639,79 & 633,82 & 870,59 \\
MED & & & & & & & & \\
LEITOS & 0,00 &, 00 & 0,012 & 0,0127 & 0,002 & 0,002 & 0,0031 & 0,0027 \\
TX_AN & 6,78 & 1,86 & 20,44 & 14,60 & 12,95 & 8,92 & 9,53 & 6,28 \\
\hline
\end{tabular}

Fonte: Dados da pesquisa, 2017.

$\mathrm{Na}$ densidade demográfica, os municípios da região apresentaram uma variação de 33,94 hab. $/ \mathrm{km}^{2}$ em 2000 para 34,86 hab. $/ \mathrm{km}^{2}$ em 2010, bem abaixo da média estadual que foi de 47,85 hab. $/ \mathrm{km}^{2}$ em 2000 e 52,25 hab. $/ \mathrm{km}^{2}$ em 2010 . Comparada a variação que houve no estado entre um período e outro, na região sudoeste foi praticamente insignificante.

A grande maioria dos municípios teve uma redução na densidade demográfica, e aqueles onde não houve redução a variação foi muito pequena, 
praticamente estável. As maiores exceções são os municípios de Pato Branco e Francisco Beltrão, que destacam-se como polos da região sudoeste.

No grau de industrialização é possível perceber que a região tem tanto os municípios que não são industrializados, com um índice de 0,0 (esse é o caso de Bela Vista da Caroba), até aqueles que tem presença forte da indústria e do setor moderno em sua economia. Esse é o caso de Ampére, que apresentou o melhor desempenho tanto em $2000(0,73)$ quanto em $2010(0,64)$. O município possui uma economia dinâmica com a presença de indústrias de móveis planejados, confecções e produtos alimentares (PREFEITURA DE AMPÉRE, 2017), o que explica seu bom desempenho comparado aos demais municípios da região.

\section{Análise discriminante}

A Figura 2 apresenta o mapa da região sudoeste com a distribuição dos grupos definidos a priori para a análise discriminante. É interessante observar no mapa que a maioria dos municípios que foram classificados como grupo 1, ou seja, aqueles que apresentaram crescimento positivo estão próximos. No entorno desses municípios com crescimento positivo estão aqueles classificados como grupo 2 e 3 , ou seja, aqueles que não apresentaram crescimento algum, ou apresentaram crescimento negativo.

$\mathrm{Na}$ Figura 2 é possível perceber também, que a maior concentração de municípios classificados como grupo 1, estão próximos as duas cidades consideradas polo na região sudoeste, os municípios de Francisco Beltrão e Pato Branco. Esse fato pode ser justificado pelo que aborda Vieira (2009), onde em seus estudos ele afirma que a medida que uma cidade cresce, ela pode influenciar o crescimento de seus vizinhos. E ainda, segundo Leite (2012), embora nas cidades maiores possa ocorrer a exclusão urbana, através da concentração humana em favelas, as pessoas continuam migrando para esses locais em busca de uma vida melhor. São nessas cidades que a população visualiza as melhores oportunidades.

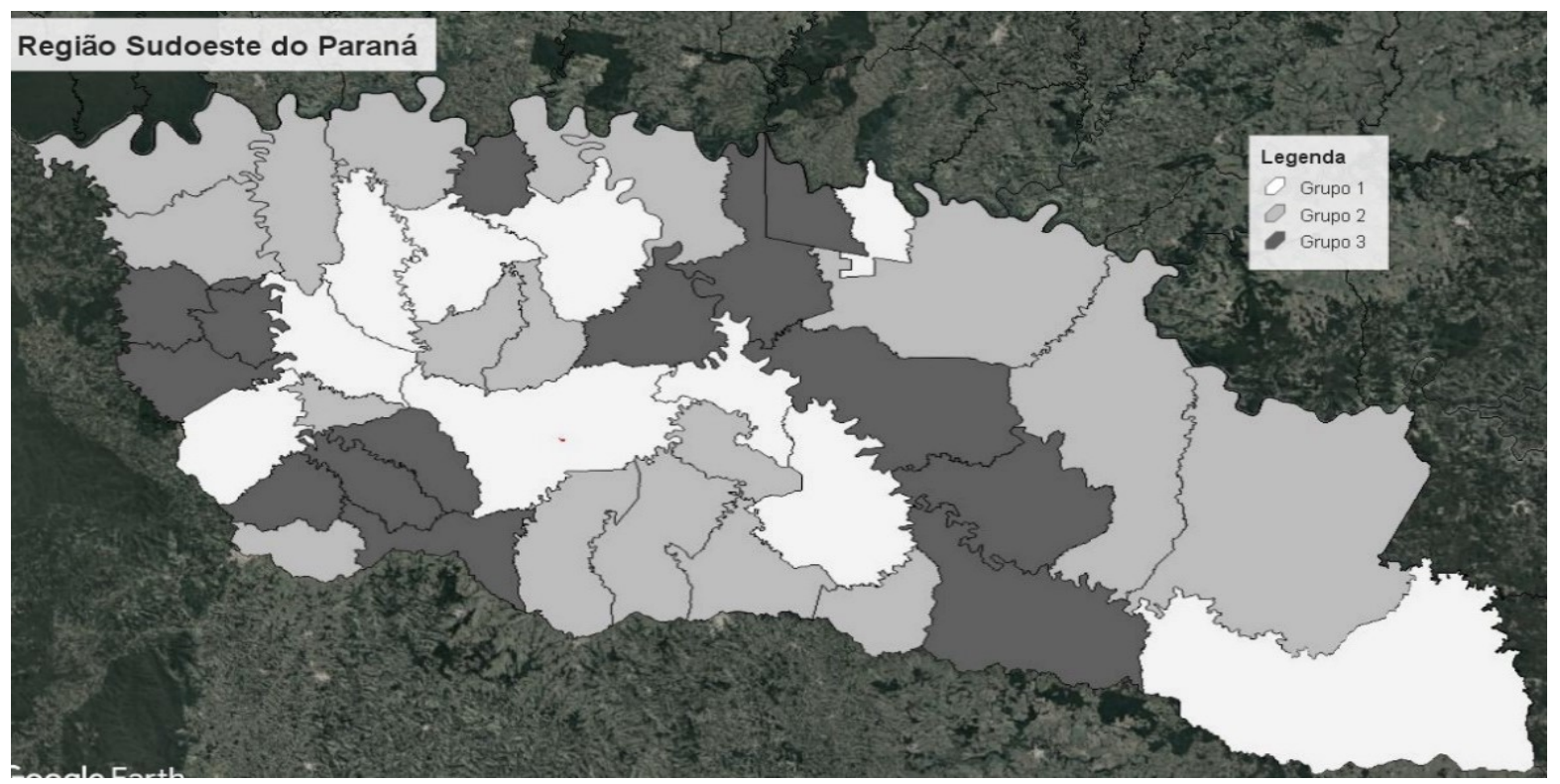

Figura 2 - Mapa com a distribuição dos grupos no Sudoeste Paranaense Fonte: Dados da pesquisa, 2017.

Conforme Moura (2004) e Firkowski (2005), a produtividade e o desempenho econômico de determinada região é favorecido pela concentração urbana, pois ela 
garante a eficiência do sistema econômico e intensifica a criatividade, a aprendizagem, a inovação e amplas possibilidades de articulação entre governo e sociedade. Desta forma, as aglomerações e os grandes centros urbanos desempenham o papel de motores do desenvolvimento econômico. Tanto Francisco Beltrão quanto Pato Branco, não são grandes metrópoles, no entanto por sua importância para a região, são cidades que possuem atrativos (educação, saúde, empregos), para o restante dos municípios ao seu redor.

A Tabela 5 apresenta os principais outputs da análise discriminante, que foram utilizados para determinar as variáveis com maior poder discriminatório em cada um dos períodos. O lambda de Wilks varia de 0 a 1, e testa a existência de diferenças de médias entre os grupos para cada variável (FÁVERO et al., 2009), quanto mais próximo de 0 , melhor a discriminação, quanto mais próximo de 1 pior o poder discriminatório da variável. Já a estatística $F$ testa a significância das variáveis, que expressa as diferenças entre as médias, sendo que os valores mais próximos de 0 indicam médias mais distintas (FÁVERO et al., 2009).

Os coeficientes discriminantes, vão avaliar qual a importância de cada variável explicativa para a função discriminante. Quanto maior o valor do peso discriminante maior a importância daquela variável para a função discriminante (FÁVERO et al., 2009).

Para determinar quais variáveis são significantes, é necessário que seja feita uma análise conjunta dos efeitos das variáveis independentes nos grupos, ou seja, cruzando os resultados do teste $\mathrm{F}$ e lambda de Wilks, com os coeficientes discriminantes. Diante disto, para o período de 2000, apenas as variáveis "densidade demográfica", "grau de industrialização" e "renda média" são estatisticamente significantes, ou seja, apenas estas três variáveis são capazes de explicar o fenômeno de crescimento ou perda de população das cidades do sudoeste paranaense. Já para o ano de 2010, fazendo essa mesma análise, as variáveis que apresentam maior significância foram "densidade demográfica", "taxa de analfabetismo", "grau de industrialização" e "domicílios com esgotamento sanitário".

Tabela 5 - Comparativo entre principais resultados da análise discriminante

\begin{tabular}{|c|c|c|c|c|c|c|c|c|}
\hline \multirow[b]{2}{*}{ Variável } & \multicolumn{4}{|c|}{2000} & \multicolumn{4}{|c|}{2010} \\
\hline & 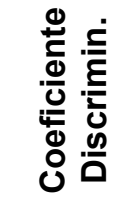 & 兑 & 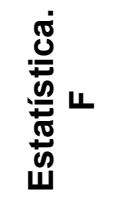 & வ் & 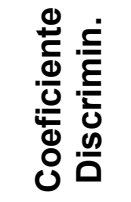 & 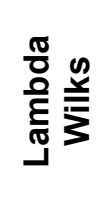 & 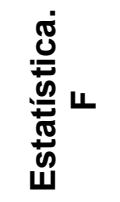 & வ் \\
\hline DENS_DEM & 0,051 & 0,640 & 10,983 & 0,000 & 0,064 & 0,574 & 14,490 & 0,000 \\
\hline THEIL_L & 4,579 & 0,953 & 0,961 & 0,392 & 3,305 & 0,943 & 1,171 & 0,321 \\
\hline DOM_ESG & $-3,215$ & 0,919 & 1,714 & 0,193 & $-0,110$ & 0,807 & 4,678 & 0,015 \\
\hline PIB_PERC. & 0,000 & 0,936 & 1,332 & 0,276 & 0,000 & 0,921 & 1,669 & 0,202 \\
\hline GI & 5,617 & 0,788 & 5,248 & 0,010 & 4,866 & 0,728 & 7,283 & 0,002 \\
\hline RENDA_MED & 0,004 & 0,739 & 6,887 & 0,003 & $-0,005$ & 0,859 & 3,195 & 0,052 \\
\hline LEITOS & $-195,75$ & 0,973 & 0,537 & 0,589 & $-44,316$ & 0,939 & 1,271 & 0,292 \\
\hline TX AN & 0,147 & 0,914 & 1,842 & 0,172 & 0,012 & 0,820 & 4,267 & 0,021 \\
\hline
\end{tabular}

Fonte: Dados da pesquisa, 2017.

Na linha referente à variável densidade demográfica, é possível perceber que ela se tornou melhor discriminante em 2010. Houve o aumento dos resultados do lambda de Wilks e do coeficiente discriminante, e a significância permaneceu com o mesmo desempenho. Esse resultado é semelhante ao que apresenta Vieira (2009), e 
também a teoria da Nova Geografia Econômica, onde aglomerações urbanas tendem a atrair um número maior de pessoas. O que justifica também, a presença desta variável em ambos os períodos, e com o maior poder discriminatório.

A segunda variável presente em ambos os períodos, o grau de industrialização, obteve um efeito diferente da densidade demográfica. Tanto no coeficiente discriminante, quanto na significância, os resultados foram melhores em 2000 que em 2010, apenas o lambda de Wilks apresentou um resultado melhor em 2010. Embora tenha havido essa redução, ainda é possível verificar que o nível de industrialização de algumas cidades do sudoeste paranaense está sendo capaz de promover seu crescimento. Resultado esse semelhante ao encontrado por Vieira (2009) e Souza, Moreira e Gasparini (2009), onde a industrialização e a presença do setor moderno em uma cidade, tem influência direta em seu crescimento.

A variável renda média familiar per capita, fez parte do período de 2000 , mas não de 2010. O resultado aqui encontrado difere do apresentado por Souza, Moreira e Gasparini (2009). Em sua pesquisa, os autores verificaram que as cidades que mais cresceram foram aquelas com menores níveis de renda média familiar per capita. $O$ oposto do que ocorreu nesta pesquisa, onde as cidades com maior renda média familiar per capita, foram as que mais cresceram, e ainda foi uma das variáveis com poder discriminatório significante para a diferenciação dos grupos.

A taxa de analfabetismo, no período inicial não se mostrou significante, no entanto no período seguinte, sim. Vieira (2009) encontrou resultados semelhantes, e uma das justificativas para esse fato, foi que os municípios que apresentam nível educacional elevado, tendem a atrair a população dos municípios vizinhos com nível educacional menor. Souza, Moreira e Gasparini (2009), também encontraram resultado semelhante. Nesta pesquisa, os municípios que fazem parte do grupo 1, são justamente aqueles que tem o maior número de instituições de ensino, desde o ensino fundamental a pós-graduação, consequentemente as taxas de analfabetismo tendem a ser menores que nos demais grupos.

A última variável incluída com forte peso discriminante trata-se da variável domicílios com esgotamento sanitário, relacionada a infraestrutura. Ao contrário de todas as outras variáveis, domicílios com esgotamento sanitário está relacionado de forma negativa ao crescimento dos municípios. Ou seja, os municípios têm apresentado crescimento populacional, no entanto a área de saneamento não tem acompanhado esse crescimento, e não sendo capaz de suprir a demanda, mesmo em municípios maiores. O resultado encontrado, diverge do que foi verificado por Souza, Moreira e Gasparini (2009). Onde não houve relação significante entre o crescimento das cidades e o número de domicílios atendidos com esgotamento sanitário.

A AD pode reclassificar as observações definidas a priori. Nesta pesquisa para o ano de 2000 , foram $66,7 \%$ dos casos classificados de forma correta, já em 2010 foram $81 \%$ classificados de forma correta, como pode ser observado na Tabela 6.

Tabela 6 - Resultado da classificação dos grupos - 2000 e 2010

\begin{tabular}{|c|c|c|c|c|c|c|c|c|c|}
\hline & \multirow{3}{*}{ Grupos } & \multicolumn{4}{|c|}{2000} & \multicolumn{4}{|c|}{2010} \\
\hline & & \multicolumn{3}{|c|}{ Grupos previstos } & \multirow{2}{*}{ Total } & \multicolumn{3}{|c|}{ Grupos previstos } & \multirow{2}{*}{ Total } \\
\hline & & 1,0 & 2,0 & 3,0 & & 1,0 & 2,0 & 3,0 & \\
\hline \multirow{3}{*}{$\begin{array}{c}\text { Classificação } \\
\text { grupos }\end{array}$} & 1,0 & 7 & 3 & 0 & 10 & 6 & 3 & 1 & 10 \\
\hline & 2,0 & 1 & 12 & 5 & 18 & 0 & 15 & 3 & 18 \\
\hline & 3,0 & 0 & 5 & 9 & 14 & 0 & 1 & 13 & 14 \\
\hline
\end{tabular}

$* * \star 66,7 \%$ dos casos foram classificados corretamente em 2000.

$* * * 81,0 \%$ dos casos foram classificados corretamente

Fonte: Dados da pesquisa, 2017. 
Nos resultados apresentados, essa reclassificação ocorreu, pois algumas observações, apesar de apresentarem a taxa de crescimento geométrico para um determinado grupo, na combinação entre todas as variáveis adotadas na pesquisa, apresentam dados muito parecidos com o de outro grupo. No ano de 2000 foram 14 dos 42 municípios reclassificados, já em 2010 foram apenas 8. Os municípios que apresentaram essa reclassificação podem ser observados na Tabela 7 . A cidade de Pranchita, por exemplo, no critério de classificação adotado inicialmente, pertence ao grupo 3, pois seu crescimento geométrico foi de $-1,06$. Na classificação feita pela AD, Pranchita passou para o grupo 2. Isso pode ser explicado pelos dados das variáveis utilizadas, pois nelas, a grande maioria (PIB per capita, número de leitos, domicílios com esgotamento sanitário, etc.) apresenta resultados muito parecidos com os municípios classificados como grupo 2. As observações que estão em negrito são aquelas que apresentaram a mesma reclassificação tanto no período de 2000 , quanto em 2010. São eles: Itapejara d'Oeste, Pinhal de São Bento, Pranchita e Salto do Lontra.

Tabela 7 - Classificação de cada município após a aplicação da AD - 2000 e 2010

\begin{tabular}{|c|c|c|c|c|c|c|c|c|}
\hline \multirow[b]{2}{*}{ Município } & \multicolumn{4}{|c|}{2000} & \multicolumn{4}{|c|}{2010} \\
\hline & 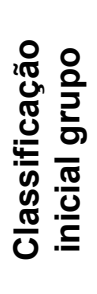 & 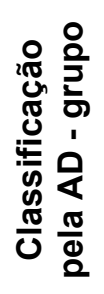 & 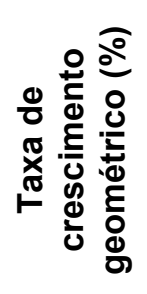 & 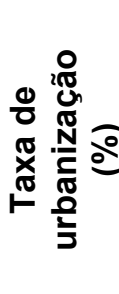 & 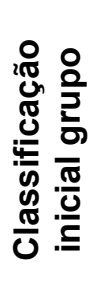 & 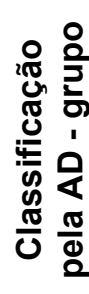 & 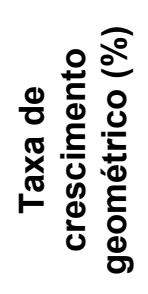 & 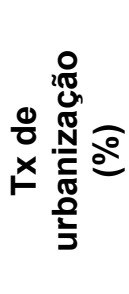 \\
\hline Barracão & 2 & 1 & 0,49 & 71,99 & & & & \\
\hline Boa Esperança do Iguaçu & 3 & 2 & $-1,16$ & 34,48 & & & & \\
\hline Clevelândia & 3 & 2 & $-0,62$ & 85,60 & & & & \\
\hline Cel. Domingos Soares & 2 & 3 & 0,33 & 24,22 & & & & \\
\hline $\begin{array}{l}\text { Cruzeiro do Iguaçu } \\
\text { Itapejara d'Oeste }\end{array}$ & 1 & 2 & 1,40 & 66,35 & $\begin{array}{l}2 \\
1\end{array}$ & $\begin{array}{l}3 \\
2\end{array}$ & $\begin{array}{l}-0,27 \\
1,40\end{array}$ & $\begin{array}{l}61,31 \\
66,35\end{array}$ \\
\hline Marmeleiro & 2 & 3 & 0,17 & 63,48 & & & & \\
\hline $\begin{array}{l}\text { Nova Esperança do } \\
\text { Sudoeste }\end{array}$ & 2 & 3 & $-0,31$ & 34,21 & & & & \\
\hline Palmas & & & & & 1 & 3 & 2,11 & 92,79 \\
\hline Pinhal de São Bento & 2 & 3 & 0,25 & 44,42 & 2 & 3 & 0,25 & 44,42 \\
\hline Planalto & & & & & 2 & 3 & $-0,34$ & 44,44 \\
\hline Pranchita & 3 & 2 & $-1,06$ & 64,05 & 3 & 2 & $-1,06$ & 64,05 \\
\hline Renascença & 2 & 3 & $-0,21$ & 51,16 & & & & \\
\hline Salto do Lontra & 1 & 2 & 0,71 & 54,28 & 1 & 2 & 0,71 & 54,28 \\
\hline Santa Izabel do Oeste & & & & & 1 & 2 & 1,15 & 56,51 \\
\hline São João & 3 & 2 & $-0,56$ & 63,54 & & & & \\
\hline Verê & 3 & 2 & $-1,01$ & 41,65 & & & & \\
\hline
\end{tabular}

Obs.: Tanto a taxa de crescimento geométrico quanto a taxa de urbanização referem-se ao ano de 2010, período utilizado para a classificação dos grupos.

Fonte: Dados da pesquisa, 2017.

Algumas variáveis, embora importantes, como PIB per capita, leitos hospitalares, etc. acabaram ficando de fora da análise por não apresentarem a significância necessária para permanecer no modelo. Resultado diferente do encontrado por Vieira (2009) e Souza, Moreira e Gasparini (2009), onde variáveis 
como PIB per capita e índice $L$ de Theil foram significantes para determinar 0 crescimento urbano das cidades.

\section{CONSIDERAÇÕES FINAIS}

Esta pesquisa se propôs a verificar quais fatores contribuíram para que alguns dos 42 municípios da região sudoeste paranaense apresentasse crescimento populacional, e outros sofressem o processo inverso com o esvaziamento populacional durante o período de 2000 e 2010. Como base teórica, foi utilizada a teoria de aglomerações defendida pela Nova Geografia Econômica, e como técnica estatística de análise, utilizou-se a análise discriminante a partir de oito variáveis. As variáveis utilizadas foram, densidade demográfica, índice de Theil-L, domicílios com esgotamento sanitário, PIB per capita, grau de industrialização, renda média domiciliar per capita, número de leitos e taxa de analfabetismo. Destas oito variáveis, nem todas foram significantes para discriminar os três grupos de municípios, bem como ocorreram diferenças entre o período inicial e final.

A partir de toda a análise e pesquisa desenvolvida, conclui-se que as variáveis que mais discriminam o crescimento urbano dos municípios são: a densidade demográfica e o grau de industrialização. Estas duas variáveis foram importantes na discriminação em ambos os períodos de estudo, sendo que a densidade demográfica foi a de maior destaque. Ou seja, as concentrações populacionais podem ser consideradas fontes de atração para uma concentração maior de indústrias, e vice e versa, além do que, a presença do setor "moderno" tende a gerar riqueza em um determinado local, e esse fato torna-se um ponto de maior atração comparado a outras regiões que não os possuem.

A variável que fez parte do período inicial, mas não do final, foi apenas a renda familiar per capita, indicando que parte da atração exercida pelos municípios mais dinâmicos sobre os demais estava relacionada à possibilidade de maiores ganhos financeiros. Já no período final, as variáveis taxa de analfabetismo e domicílios com esgotamento sanitário passam a fazer parte das variáveis discriminatórias. A presença de ambas pode indicar a mudança no perfil tanto da população quanto de empresas, onde não apenas a possibilidade de altos ganhos financeiros é fator de atração, mas também a possibilidade de uma qualidade de vida melhor. Para as empresas, locais com menores taxas de analfabetismo podem indicar pessoas mais preparadas para assumir cargos importantes, e que exijam uma maior preparação.

Os resultados apresentados são um indício de que cada vez mais as pessoas buscam se aglomerar e estar perto dos locais onde há os maiores recursos. No entanto, esses locais com maiores recursos, não necessariamente são as maiores metrópoles do país. Prova deste fato, é a diferença de crescimento populacional do estado do Paraná como um todo e o crescimento da região Sudoeste para o ano de 2010, onde a região obteve um crescimento significativamente maior, se comparado ao estado.

Apesar da pesquisa desenvolvida ter apresentado resultados interessantes quanto ao crescimento urbano da região sudoeste do Paraná, há várias direções em que ela pode ser ampliada. Podem ser adicionadas novas variáveis relacionadas aos fluxos migratórios da população, pobreza, segurança pública, gastos públicos nos diversos setores da economia, infraestrutura urbana (ruas asfaltadas, coleta de resíduos) e impactos ambientais. Também sugere-se que a área de análise seja ampliada para todo o estado, desta forma será possível analisar as características de crescimento de cada mesorregião. Quanto à análise estatística, na pesquisa utilizou- 
Análise dos fatores discriminantes do crescimento urbano dos municípios do Sudoeste do Paraná no período 20002010

se a análise discriminante, de modo que em novas pesquisas podem ser utilizados outros métodos e ferramentas.

\section{REFERÊNCIAS}

BAENINGER, Rosana; A Nova Configuração Urbana no Brasil: Desaceleração Metropolitana e Redistribuição da População, 09/2011, ed. 1, 1, Max Limonad, Vol. 1, pp.46-70, 2011. Disponível em:

$<$ http://www.abep.org.br/publicacoes/index.php/anais/article/view/863/829>. Acesso em: 03 nov. 2017.

CINTRA, Anael Pinheiro de Ulhôa et al. Primeiras impressões sobre o censo 2010 no Paraná. Revista Paranaense de desenvolvimento, n.118, p.113-138, jan./jun. 2010. Disponível em:

<http://www.ipardes.pr.gov.br/ojs/index.php/revistaparanaense/article/view/242>. Acesso em: 02 out. 2017.

CORRAR, Luiz João; PAULO, Edilson; DIAS FILHO, José Maria (Coord.). Análise multivariada: para os cursos de administração, ciências contábeis e economia. São Paulo: Atlas, 2007.

COSTA, Fabio Rodrigues da; ROCHA, Márcio Mendes. Nova dinâmica dos municípios do Paraná. Mercator, Fortaleza, v. 13, n. 2, p. 91-104, mai./ago. 2014. Disponível em: <www.scielo.br/pdf/mercator/v13n2/1676-8329-mercator-13-020091.pdf>. Acesso em: 30 out. 2017.

CRUZ, Bruno de Oliveira. Uma Breve Incursão em Aspectos Regionais da Nova Geografia Econômica. In: IPEA, 2011.

DANTAS, Joseney Rodrigues de Queiroz; CLEMENTINO, Maria do Livramento Miranda. O papel das cidades (inter) médias para o desenvolvimento regional: um estudo a partir dos centros sub-regionais (Pau dos Ferros-RN, Cajazeiras-PB e Sousa-PB). Geo UERJ - Ano 15, nº. 24, v. 1, $1^{\circ}$ semestre de 2013 p. 228-255.

ELIAS, Denise; PEQUENO, Renato. Reestruturação Econômica e Nova Economia Política da Urbanização no Ceará. Mercator, Fortaleza, v. 12, n. 28, p. 95-112, mai./ago. 2013. Disponível em: http://www.redalyc.org/articulo.oa?id=273628671008>. Acesso em: 17out. 2017.

FÁVERO, Luiz Paulo Lopes et al. Análise de dados: modelagem multivariada para a tomada de decisões. 1. ed. Rio de Janeiro: Elsevier, 2009.

FIRKOWSKI, Olga Lucia C. de Freitas. Dinâmica populacional e urbanização. In: Paraná espaço e memória: diversos olhares históricos geográficos. Organizadores: Claudio Joaquim Rezende, Rita Inocêncio Triches. Curitiba: Editora Bagozzi, 2005.

FLORES, Edson Luiz. Industrialização e desenvolvimento do Sudoeste do Paraná. 226f. Dissertação (Mestrado em Geografia), Universidade Estadual do Oeste do Paraná - UNIOESTE, Francisco Beltrão - PR, 2009. 
FUJITA, Masahisa; KRUGMAN, Paul; MORI, Tomoya. On the evolution of hierarchical urban Systems. European Economic Review 43 (1999) 209-251.

FUJITA, Masahisa; KRUGMAN, Paul; VENABLES, Anthony J. Economia Espacial, Urbanização, prosperidade econômica e desenvolvimento humano no mundo. São Paulo: Futura, 2002.

HAIR, Joseph F.; et al. Análise Multivariada de Dados. $5^{\circ}$ ed. Porto Alegre:

Bookman, 2005. Disponível em:

http://docs11.minhateca.com.br/190469330,BR,0,0,Livro---ANALISE-

MULTIVARIADA-DE-DADOS---Hair-et-al.pdf. Acesso em: 31 jul. 2017.

INSTITUTO PARANAENSE DE DESENVOLVIMENTO ECONÔMICO E SOCIAL IPARDES. Leituras regionais: mesorregiões geográficas do Paraná. Curitiba, 2004. Disponível em: <

http://www.ipardes.gov.br/index.php?pg conteudo=1\&sistemas=1\&cod sistema=1\&a no estudo=2004>. Acesso em: 30 abr. 2017.

INSTITUTO BRASILEIRO DE GEOGRAFIA E ESTATÍSTICA - IBGE. Sinopse do Censo Demografico 2010 - Brasil. Disponível em:

<https://censo2010.ibge.gov.br/sinopse/index.php?dados=8>. Acesso em: 10 out. 2017.

IPEA, IBGE, UNICAMP / IE / NESUR, IPARDES. Caracterização e tendências da rede urbana do Brasil: redes urbanas regionais: Sul. Brasília: IPEA, 2000.

Disponível em: <http://www.ipardes.pr.gov.br/imp/imp.php?page=locinfpop>. Acesso em 12 de maio de 2017.

KRUGMAN, Paul. On the number and location of cities. European Economtc Review 37 (1993) 293-298. North-Holland.

LEITE, Carlos. Cidades sustentáveis, cidades inteligentes: desenvolvimento sustentável num planeta urbano. Porto Alegre: Bookman, 2012.

LEME, Ricardo Carvalho. Expansão Urbana e Verticalização: O Mercado Imobiliário de Francisco Beltrão/PR (1998 a 2012). 364 f. Tese (Doutorado em Geografia), Universidade Federal de Santa Catarina - UFSC, Florianópolis - SC, 2015. Disponível em: < https://repositorio.ufsc.br/xmlui/handle/123456789/156750>. Acesso em: 17 out. 2016.

MATOS, Ralfo; BAENINGER, Rosana. Migração e urbanização no Brasil: processos de concentração e desconcentração espacial e o debate recente. Cadernos do Leste, v. 1, n. 1, p. 7-44, 2004. Disponível em:

<http://www.igc.ufmg.br/portaldeperiodicos/index.php/leste/article/view/795>. Acesso em: 03 nov. 2017.

MONDARDO, Marcos Leandro. Uma caracterização geral do processo de urbanização no sudoeste do Paraná - Brasil. Scripta Nova - Revista electrónica de geografia y ciências sociales. Universidad de Barcelona. Vol. XI, núm. 239, 15 
de mayo de 2007. Disponível em: <http://www.ub.edu/geocrit/sn/sn-239.htm>. Acesso em: 15 abril de 2017.

MONDARDO, Marcos Leandro. BACKES, Thaine Regina. As migrações e as transformações territoriais e as transformações territoriais no sudoeste do Paraná. Revista Faz Ciência, v. 9, n. 9, Jan./Jul. 2007, p. 35-58.

MONDARDO, Marcos Leonardo. A dinâmica migratória do Paraná: o caso da região Sudoeste ao longo do século XX. Revista brasileira Estudos Populacionais, Rio de Janeiro, v. 28, n. 1, p. 103-131, jan./jun. 2011.

MOURA, Rosa. Paraná: meio século de urbanização. Revista RA'EGA, Curitiba, n. 8, p. 33-44, 2004. Editora UFPR. Disponível em:

<revistas.ufpr.br/raega/article/view/3381>. Acesso em: 22 set. 2017.

NAÇÕES UNIDAS. Fatos sobre as cidades. Produzido pelo Departamento de Informação Pública das Nações Unidas, junho de 2012. Disponível em: <www.onu.org.br/rio20/cidades.pdf>. Acesso em: 05 mai. 2017.

OLIVEIRA, Cristiano. Desigualdades regionais no Rio Grande do Sul: um enfoque da Nova Geografia Econômica. Redes, Santa Cruz do Sul, v. 10, n. 2, p. 93-116, maio/ago. 2005. Disponível em:

$<$ https://online.unisc.br/seer/index.php/redes/article/viewFile/11070/6787>. Acesso em: 25 out.2017.

ROLNIK, Raquel; KLINK, Jeroen. Crescimento econômico e desenvolvimento urbano: Por que nossas cidades continuam tão precárias? Novos estudos, n. 89, p. 89-109, 2011. Disponível em: < http://www.scielo.br/pdf/nec/n89/06.pdf>. Acesso em: 10 fev. 2017.

SILVA, Ariana Cericatto da; BULHÕES, Ronaldo. Quociente locacional: Uma Análise dos Setores Econômicos nas mesorregiões Paranaenses entre 1999 e 2008. VI Encontro de Economia Catarinense Inovação e Desenvolvimento, Joinville, 2012.

SOUZA, Fábia Oliveira Martins de; MOREIRA, Tito Belchior Silva; GASPARINI, Carlos Eduardo. Crescimento econômico urbano nos municípios brasileiros médios e grandes. Economia e Desenvolvimento, Recife (PE), v.8 n. 1, 2009.

THISSE, Jacques-François. Geografia Econômica. In Economia regional e urbana: teorias e métodos com ênfase no Brasil / organizadores: Bruno de Oliveira Cruz ... [et al.]. - Brasília: Ipea, 2011.

UNITED NATIONS. Department of Economic and Social Affairs, Population Division. World Urbanization Prospects: The 2014 Revision, CD-ROM Edition, 2014. Disponível em: < https://esa.un.org/unpd/wup/CD-ROM/. Acesso em: 05 mai. 2017.

VIEIRA, Rodrigo de Souza. Crescimento econômico no estado de São Paulo: uma análise espacial [online]. São Paulo: Editora UNESP; São Paulo: Cultura

Acadêmica, 2009. 103 p. Disponível em: <http://books.scielo.org>. Acesso em: 10 fev. 2017.23 